\title{
Gametangium-like Structures as Propagation Buds in Codium edule Silva (Bryopsidales, Chlorophyta) ${ }^{1}$
}

\author{
Jui-Sheng Chang ${ }^{\mathrm{a}, \mathrm{b}}$, Chang-Feng Dai ${ }^{\mathrm{a} *}$ and Jeng Chang ${ }^{\mathrm{c}}$ \\ a Institute of Oceanography, National Taiwan University, Taipei 106, Taiwan, e-mail: corallab@ccms.ntu.edu.tw \\ b Center for General Education, Yuda Institute of Business Technology, Miaoli 361, Taiwan \\ ${ }^{c}$ Institute of Marine Biology, National Taiwan Ocean University, Keelung 202, Taiwan \\ * Corresponding author
}

\begin{abstract}
Gametangium-like structures were found on the sides of utricles of Codium edule collected during the latter period of its growing season in southern Taiwan. They are usually fusiform and bigger than the regular gametangia, but do not contain gametes. In addition, the gametangium-like structures bear protuberances on their surface, a character not observed in regular gametangia. In culture, the protuberances extended into filaments that developed new utricles terminally after two weeks. This indicates that the gametangium-like structures, named propagation buds, have the potential to form new thalli and can be regarded as an effective reproductive structure. In the field, the abundance of both gametangia and propagation buds on the macrothalli of C. edule was highest towards the end of its growing season, in August. Microspectrophotometric studies with DAPI showed that relative fluorescent units of nuclei in propagation buds were similar in number to those in the utricles, and were higher than those in the gametangia. We suggest that the propagation buds are possibly transformed gametangia with incomplete meiosis. The propagation buds may serve as a persistent stage when the macrothalli disintegrate at the end of the growing season, and act as a "seed bank" for vegetative reproduction for $C$. edule in the next season.
\end{abstract}

Keywords: Bryopsidales; Chlorophyta; Codium edule; gametangia; propagation bud.

Abbreviations: DAPI, 4',6-diamidino-2-phenylindole; PES, Provasoli's enriched seawater; RFU, relative fluorescence unit.

\section{Introduction}

The life cycle of the siphonous green alga Codium Stackhouse is generally known to be monomorphic and diplobiontic (Hori 1994, Van den Hoek et al. 1995). Gametangia, which develop laterally from utricles, produce gametes following meiosis. The dark-green female gamete is larger than the yellowbrown male gamete (Borden and Stein 1969, Van den Hoek et al. 1995). Sexual reproduction of Codium is based on the anisogamous biflagellate gametes fusing and the resulting zygote germinating to form a siphonous filament, which eventually develops into the familiar thallus.

Asexual reproduction of Codium, however, can be observed in some species. Three modes of asexual reproduction have been reported in Codium in nature: by the production of "Brutkörper" (propagation buds) in C. isthmocladum Vickers (Schmidt 1923, Silva 1960), by fragmentation (Silva 1957, in C. fragile subsp. scandinavicum P.C. Silva; Fralick and Mathieson 1972, in C. fragile subsp. tomentosoides [van Goor] P.C. Silva), and by "swimming cell reproduction" (i.e., parthenogenetic gametes) in $C$. fragile sub-

\footnotetext{
$\overline{{ }^{1} \text { Submitted } 22}$ October 2002; accepted 30 June 2003.
}

sp. tomentosoides (Malinowski and Ramus 1973). Recently, the formation and growth of filamentous thalli from isolated utricles with medullary filaments has also been described for $C$. fragile (Suringar) Hariot in cultivation (Yotsui and Migita 1989, Yang et al. 1997, Nanba et al. 2002), and was suggested as a mode of vegetative reproduction. It seems that Codium species may reproduce via both sexual and asexual modes, and such reproductive modes vary with species and geographic populations. However, most of the asexual modes of macrothallus formation are known in C. fragile and its subspecies (reviewed in Trowbridge 1998). The reproduction and life cycle of other Codium species have rarely been studied.

Codium edule Silva is one of the prostrate and branching species widely distributed on tropical reefs in the Indo-Pacific area (Silva 1952, Silva et al. 1987, Silva et al. 1996). The macrothalli of $C$. edule are often initiated in late winter, flourish in spring, and reach maximum biomass in April and May in southern Taiwan. Most of the macrothalli disappear in June to August when the southern monsoon prevails and the rainy season begins. During the past decade, the macrothalli of $C$. edule have spread rapidly on reefs in Nanwan Bay, southern Taiwan, and form dense meadows every year (Chiang and Wang 1987, 
Dai 1997). The annual mass production of $C$. edule has been suggested as one of the factors responsible for the degradation of coral reefs in Nanwan Bay (Dai 1997). However, the gametangia of this alga have been found rarely during the growing season, despite intensive laboratory examinations of macrothalli collected from the field (Chang et al. 2002). A few gametangia were found on thalli collected at the end of the growing season in 2000, but their sex could not be distinguished under a microscope by following the methods described in Borden and Stein (1969) and Ramus (1972). Therefore, the reproduction of $C$. edule and how it leads to mass production cannot be explained by the known reproductive modes proposed for Codium species (Churchill and Moeller 1972). In this paper we describe the formation and growth of filaments and utricles from a gametangium-like structure and propose its role in the life cycle of $C$. edule based on morphological and microspectrophotometric studies.

\section{Material and Methods}

Macrothalli of Codium edule (Fig. 1) were collected from Nanwan Bay, southern Taiwan (21. $57^{\prime} \mathrm{N}, 120^{\circ}$ $46^{\prime} \mathrm{E}$ ) by SCUBA during the growing season in 2000 and 2001. They were transported in seawater to the laboratory within $6 \mathrm{~h}$. Epiphytes were removed, and the thalli were then kept in an aquarium with filtered seawater and aerated before observation and further culturing.

In order to determine the occurrence and abundance of reproductive structures, the apical sections $(3-5 \mathrm{~cm})$ from the branches of each collected thallus of Codium edule were cut off and preserved in $4 \%$ formaldehyde. The reproductive structures were harvested from the preserved samples by grinding the branches with $100 \mathrm{ml}$ of filtered seawater for 25-30 s in a Waring blender (Churchill and Moeller 1972). The respective numbers of gametangia and gametangium-like structures from each thallus were then counted under a microscope.

For further cultivation of reproductive structures, gametangia and gametangium-like structures were obtained from fresh thalli following the method of Churchill and Moeller (1972). The quick grinding method effectively separated the reproductive structures from utricles without causing significant damage. The reproductive structures suspended in the solution were isolated using a capillary tube with the aid of a dissecting microscope, and cleaned four to five times with sterile seawater. The gametangia were exposed to low temperature $\left(2-4 \mathrm{~h}\right.$ at $\left.10^{\circ} \mathrm{C}\right)$ to stimulate the release of gametes, following the procedures of Borden and Stein (1969).

The gametangia or gametangium-like structures were cleaned and cultured in petri dishes using PES medium (Provasoli 1968). They were maintained in a growth chamber at a temperature of $22^{\circ} \mathrm{C}$ and a photon irradiance level of approximately $65 \mu \mathrm{mol}$ photons $/ \mathrm{m}^{2} / \mathrm{s}$ in a 12:12 h L:D photoperiod. The PES medium was changed every two days and the morphological changes of these reproductive structures were recorded with a digital camera (Coolpix 990, Nikon).

Microspectrophotometric studies were used to determine the ploidy of different stages in the life cycle of $C$. edule. The isolated utricles, gametangia, and gametangium-like structures were fixed immediately in $0.5 \%$ glutaraldehyde seawater solution for $24 \mathrm{~h}$. The materials were then transferred into $100 \%$ methanol for preservation at $4{ }^{\circ} \mathrm{C}$. Before staining, methanol was removed by evaporation and the gametangia or gametangia-like structures were crushed. They were then stained with $0.5 \mu \mathrm{g} \mathrm{ml} \mathrm{m}^{-1}$ DAPI in McIlvaine buffer ( $\mathrm{pH} 4.4$ ) for $30 \mathrm{~min}$, and examined with a Nikon fluorescence microscope (Chang and Carpenter 1988). Photographs were taken using a digital camera with a fixed shutter speed and aperture to avoid possible influences of different exposure time on the RFU. The digitized photographs were then analyzed using image analysis software (Image-Pro Plus, Media Cybernetics). The images of DAPI-stained nuclei were separated from the background with a threshold light intensity, and the integrated light intensity of the nuclear region was measured for each nucleus.

\section{Results}

During the early to middle part of the growing season, from January to May 2000, the gametangia of Codium edule were rarely found in approximately two hundred sampled thalli. However, towards the end of the growing season, in August and September 2000 , both gametangia and gametangium-like structures were found laterally on the utricles in the remaining samples of $C$. edule thalli (Fig. 2). These two structures were ovoid to fusiform, and they could be distinguished, under a microscope on the basis of their size and color. The gametangium-like structure was fresh-green, with an average length and width of $327.91( \pm 23.25) \mu \mathrm{m}$ and $184.17( \pm 15.78) \mu \mathrm{m}(\mathrm{n}=22)$, respectively. The gametangium was dark-green, and smaller in size with the average length and width of $297.98( \pm 29.56) \mu \mathrm{m}$ and $121.67( \pm 15.61) \mu \mathrm{m}$, respectively $(\mathrm{n}=14)$ (Fig. 3). There was a significant difference between the sizes of these two structures $(\mathrm{P}<$ 0.01, Mann-Whitney $U$ test). In addition, the gametangium-like structures had protuberances and extending filaments, while the gametangia did not have these structures (Figs 4,5). After 1-3 days of cultivation in PES medium, the gametangium-like structures sprouted filaments from the protuberances, mainly from those at the tip or bottom (Figs $6-8)$. The first utricle with a septum developed from a filament after about 14 days in culture (Fig. 9). Af- 


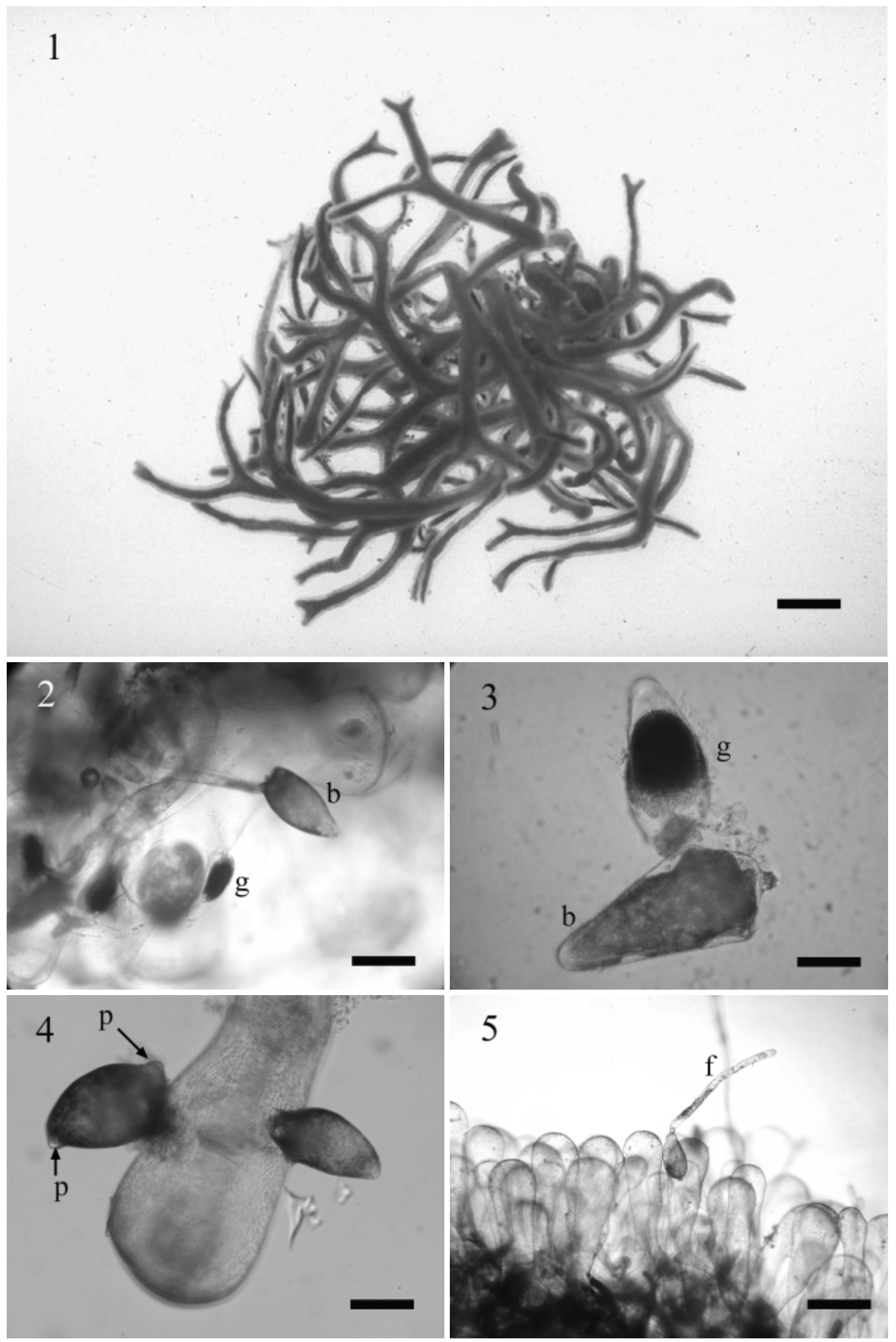

Figs 1-5. Thallus of Codium edule and its reproductive organs.

Fig. 1. The habit of Codium edule. Scale bar $=3 \mathrm{~cm}$. Fig. 2. Immature gametangium ( $\mathrm{g}$ ) and gametangium-like structure (b) growing on the side of utricle. Scale bar $=300 \mu \mathrm{m}$. Fig. 3. Separated immature gametangium $(\mathrm{g})$ and gametangium-like structure (b). Scale bar $=220 \mu \mathrm{m}$. Fig. 4 . Gametangium-like structure with protuberances (p). Scale bar $=200 \mu \mathrm{m}$. Fig. 5. A filament (f) sprouted from the gametangium-like structure on the side of utricle. Scale bar $=400 \mu \mathrm{m}$. 

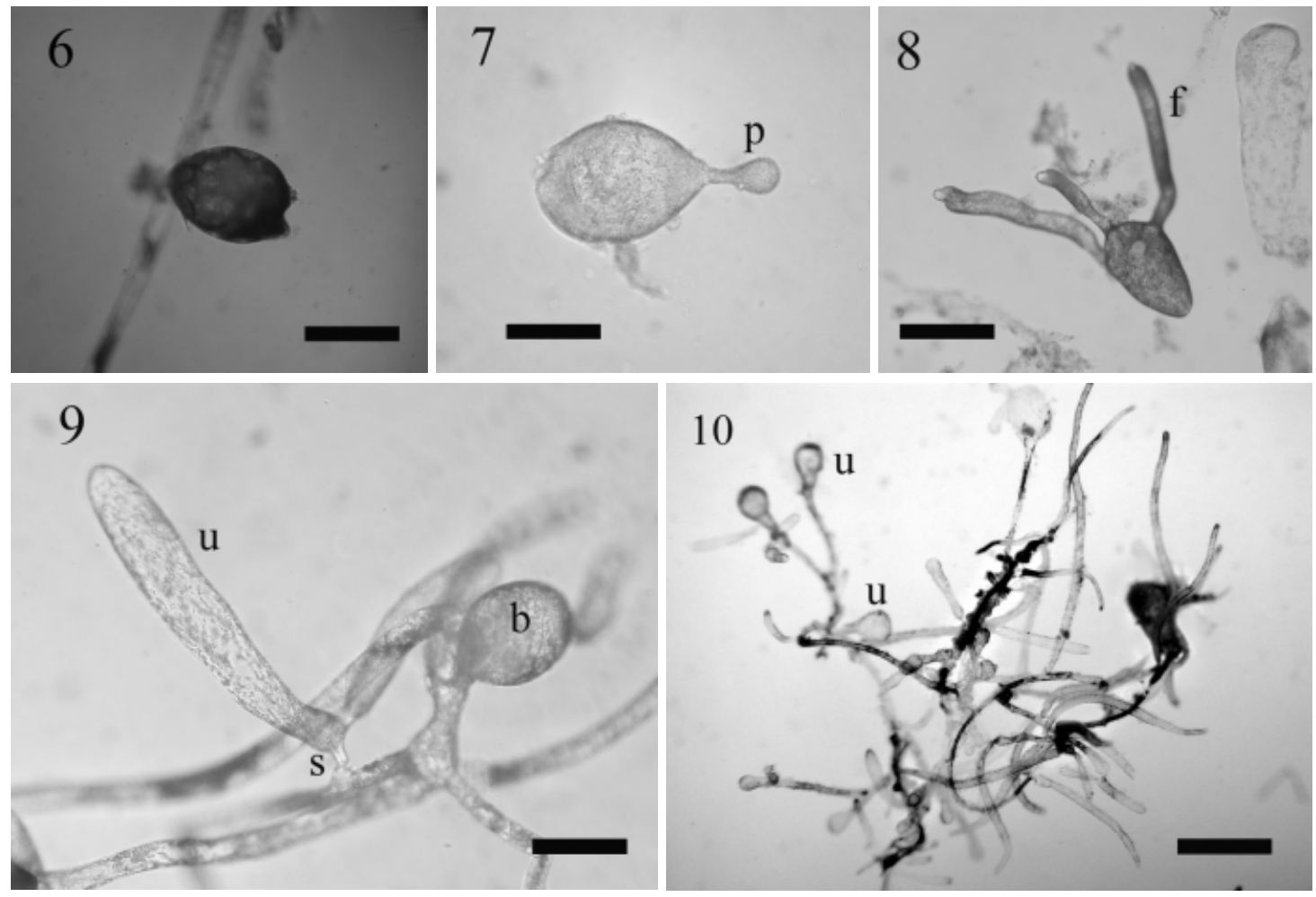

Figs 6-10. Codium edule. Culture of gametangium-like structures (b) in PES medium.

Figs 6-8. Fusiform shape of a gametangium-like structure with protuberances (p) or filaments (f) after culture for $1-3$ days. Scale bar $=300 \mu \mathrm{m}$. Fig. 9 . New utricle (u) formed and septum (s) that divides the utricle and medullary filament after 14 days in culture. Scale bar $=220 \mu \mathrm{m}$. Fig. 10. Clavate utricles (u) formed after 28 days in culture. Scale bar $=1.3 \mathrm{~mm}$.

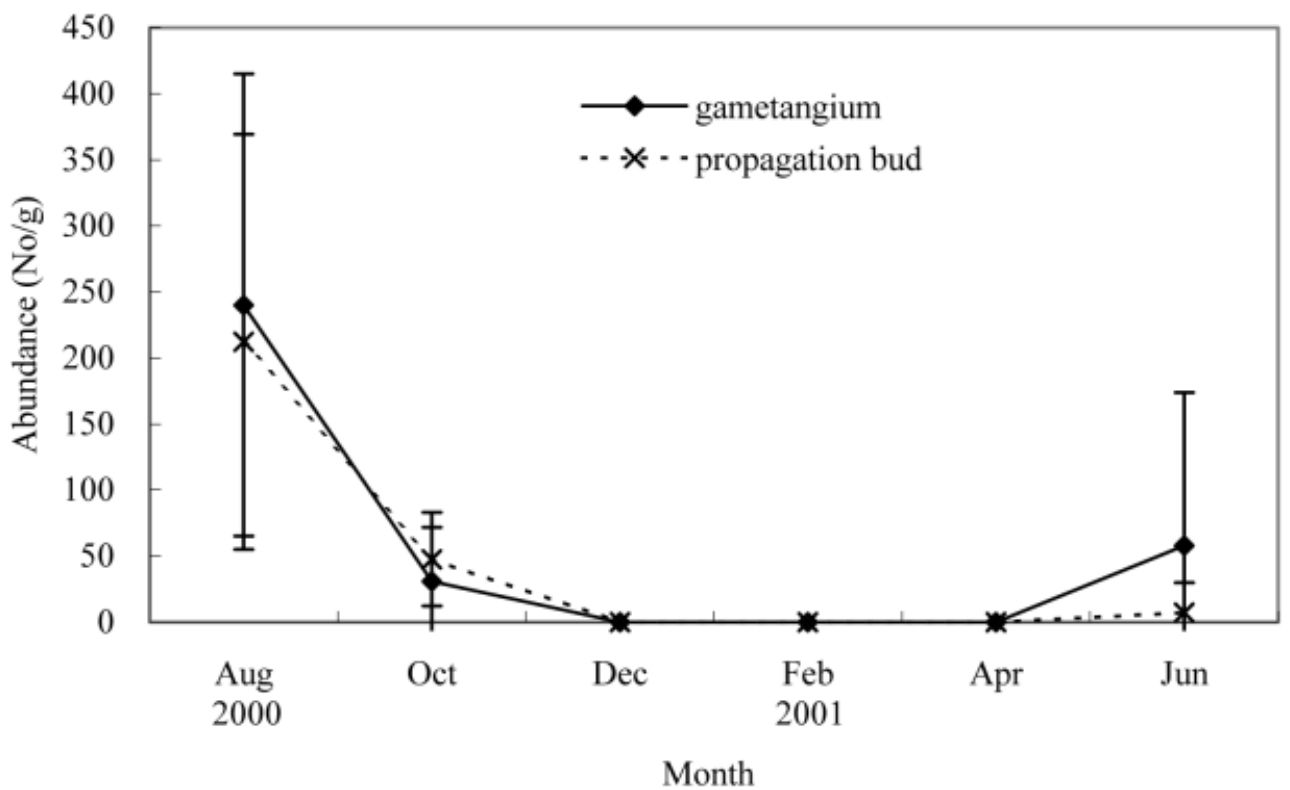

Fig. 11. The abundance of gametangia and propagation buds in Codium edule collected from Nanwan Bay, southern Taiwan from August 2000 to June 2001.

ter 28 days, more utricles were found growing from the filaments. After this period, observations were terminated due to contamination by epiphytic red algae. From these observations, we consider that the gametangium-like structure (hereafter referred to as a propagation bud) can serve as a reproductive organ and can develop directly into a mature thallus. The developmental processes described above did not occur in those gametangia cultured in the same PES medium. 
The gametangia and propagation buds on C. edule, collected from southern Taiwan, occurred from June to October (Fig. 11). The relative abundance of gametangia and propagation buds was highest in $\mathrm{Au}-$ gust $2000(240.0 \pm 174.9$ and $212.3 \pm 157.1$ per gram of tissue, respectively).

Microspectrophotometric measurements of RFU of nuclei in the gametangia, propagation buds and utricles showed that their total DNA contents were variable (Fig. 12A). The peaks of RFU data showed that the nuclei of small cells from gametangia were haploid, and those from the nuclei of filaments in propagation buds and utricles were diploid (Fig. 12B,C). This suggests that meiosis may have oc- curred in the gametangium, and that the propagation bud is possibly a transformed gametangium with an incomplete gametogenesis or meiosis.

\section{Discussion}

The propagation bud is a reproductive structure newly described for Codium edule. It differs from a gametangium by its larger size, darker color and higher DNA content. It could also be distinguished from the gametangium by the absence of gametes and apical openings. In addition, the propagation buds were able to germinate with extending filaments after culturing
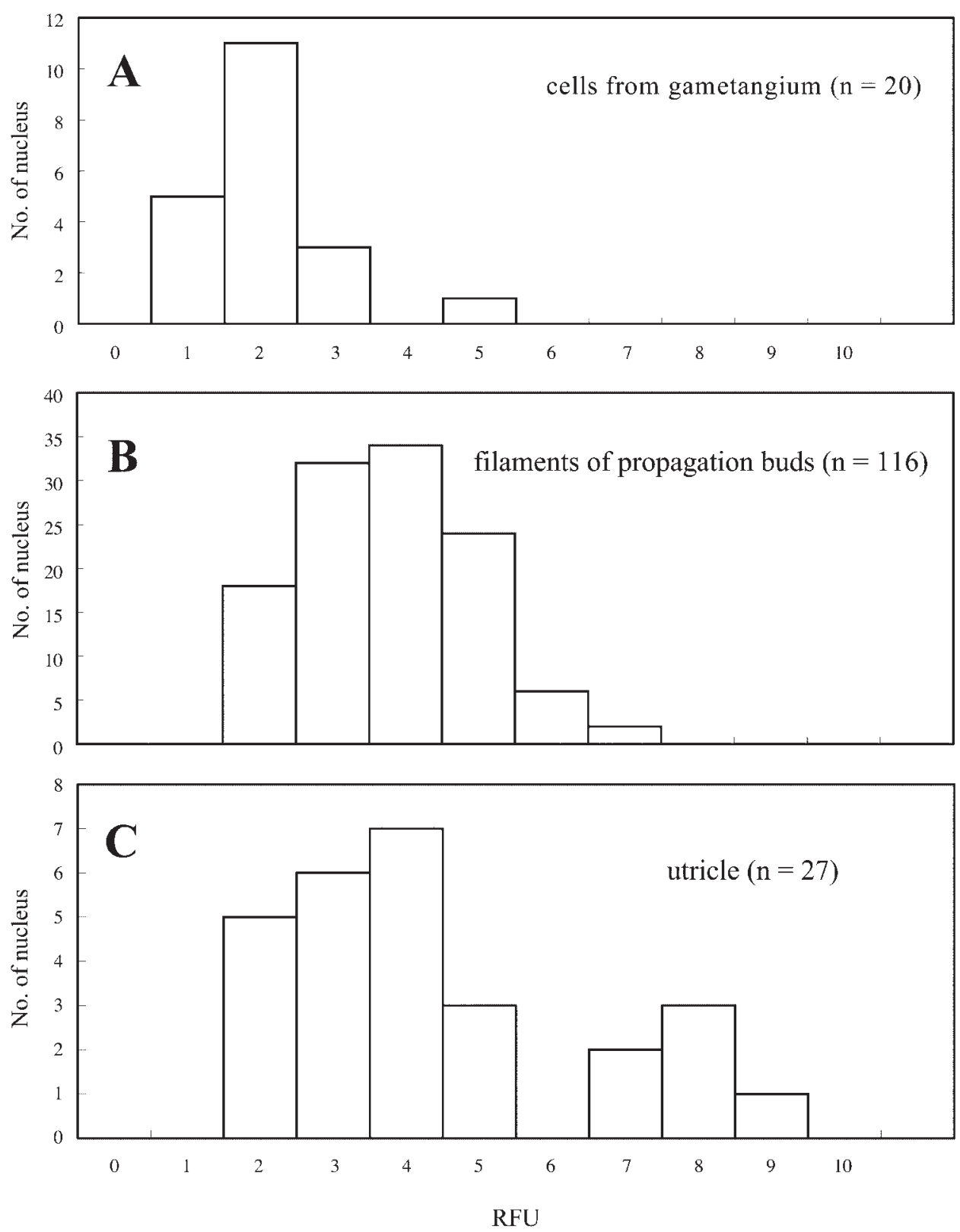

Fig. 12. Relative fluorescence unit (RFU) of nuclear DNA contents of cells from gametangium (A), filaments of propagation buds (B), and a utricle from the thallus (C) of Codium edule. 
in PES medium, while the gametangia failed to do so. The propagation buds are regarded as a reproductive organ because they can initiate siphonous filaments, and utricles can further develop from the distal ends of these filaments, which represent the initial stage of thallus formation. Structures similar to the propagation buds have been reported in C. vermilara (Olivi) delle Chiaje (as C. tomentosum in Went 1889), and $C$. ithmocladum Vickers from the Caribbean (Schmidt 1923, Silva 1960). However, the present study is the first to show that the propagation buds can germinate and act as a reproductive structure.

Male and female gametangia of Codium species are known from Pacific populations of $C$. fragile in British Columbia (Borden and Stein 1969) and Japan (Arasaki et al. 1955) based on size differences of their gametes. The propagation bud with different sized cells found in this study was similar to that described by Prince (1988), and is regarded as an aborted gametangium (Trowbridge 1998, P.C. Silva pers. com.). However, the cells inside the propagation buds were not swimming cells and they contained the same amount of nucleic acids as the utricles. We speculate

\section{References}

Arasaki, S., H. Tokuda and K. Fujiama. 1955. The reproduction and morphology in Codium fragile. Bot. Mag. Tokyo 69:39-45.

Borden, C.A. and J.R. Stein. 1969. Reproduction and early development in Codium fragile (Suringar) Hariot: Chlorophyceae. Phycologia 8: 91-99.

Chang, J. and E.J. Carpenter. 1988. Species-specific phytoplankton growth rates via diel DNA synthesis cycles II. DNA quantification and model verification in the dinoflagellate Heterocapsa triquetra. Mar. Ecol. Prog. Ser. 44:287-296.

Chang, J.S., C.F. Dai and J. Chang. 2002. A taxonomic and karyological study of the Codium geppiorum complex (Chlorophyta) in southern Taiwan, including the description of Codiun nanwanense sp. nov. Bot. Bull. Acad. Sin. 43: 161-170.

Chiang, Y.M. and W.L. Wang. 1987. Distribution of seaweeds of Hengchun Peninsula, Taiwan. In: (K.H. Chang, ed.) Marine Science. National Science Council Symposium Series, vol. 10. National Sun Yat-sen University, Kaohsiung. pp. 71-87 (in Chinese).

Churchill, A.C. and H.W. Moeller. 1972. Seasonal patterns of reproduction in New York populations of Codium fragile (Sur.) Hariot subsp. tomentosoides (Van Goor) Silva. J. Phycol. 8:147-152.

Dai, C.F. 1997. Assessment of the present health of coral reefs in Taiwan. In: (R.W. Grigg and C. Birkeland, eds) Status of Coral Reefs in the Pacific. Sea Grant Program, University of Hawaii. pp. 123-131.

Fralick, R.A. and A.C. Mathieson. 1972. Winter fragmentation of Codium fragile (Suringar) Hariot ssp. tomentosoides (Goor) Silva (Chlorophyceae, Codiales) in New England. Phycologia 11: 67-70.

Hori, T. 1994. An Illustrated Atlas of the Life History of Al- that incomplete meiosis may have occurred during the formation of these propagation buds. The propagation buds can then be regarded as transformed gametangia.

The propagation buds were mainly found during the latter period of the growing season of C. edule. The abundance of propagation buds in the field suggests that they may serve as a persistent stage or "seed bank" when the macrothalli disintegrated during the end of their growing season. Their potential to form new utricles and macrothalli further suggests that they may act as an effective mechanism of vegetative reproduction that can lead to mass production of $C$. edule during its next growing season.

\section{Acknowledgements}

We thank Drs. P.C. Silva and L.M. Liao, for their constructive comments on the previous draft of this manuscript. This study was supported by the National Science Council, R.O.C. (NSC 88-2611-B-002-002B22).

gae. Vol. 1: Green Algae. Uchida Rokakuho Publishing Co., Japan. pp. 367.

Malinowski, K.C. and J. Ramus. 1973. Growth of the green alga Codium fragile in a Connecticut estuary. J. Phycol. 9:102-110.

Nanba N., R. Kado and H. Ogawa. 2002. Formation and growth of filamentous thalli from isolated utricles with medullary filaments of Codium fragile sponge thalli. Aquat. Bot. 73:255-264.

Prince, J.S. 1988. Sexual reproduction in Codium fragile ssp. tomentosoides (Chlorophyceae) from the northeast coast of North America. J. Phycol. 24:112-114.

Provasoli, L. 1968. Media and prospects for the cultivation of marine algae. In: (A. Watanabe and A. Hattori, eds) Cultures and Collections of Algae. Proceed. U.S.-Japan Conf., Hakone. Japanese Society of Plant Physiology, Kyoto. pp. 63-75.

Ramus, J. 1972. Differentiation of the green alga Codium fragile. Amer. J. Bot. 59:478-482.

Schmidt, O.C. 1923. Beiträge zur Kenntnis der Gattung Codium Stackh. Bibl. Bot. Heft 91. pp. 68, figs 44.

Silva, P.C. 1952. Codium Stackhouse. In: (L.E. Egerod, ed.) An Analysis of the Siphonous Chlorophycophyta with Special Reference to the Siphonocladales, Siphonales, and Dasycladales of Hawaii. University of California Publications in Botany Berkeley 25. pp. 381-395.

Silva, P.C. 1957. Codium in Scandinavian waters. Svensk Botanisk Tidskrift 51:117-134.

Silva, P.C. 1960. Codium (Chlorophyta) of the tropical western Atlantic. Nova Hedwigia 1: 497-536.

Silva, P.C., E.G. Meñez and R.L. Moe. 1987. Catalog of the Benthic Algae of the Philippines. Smithsonian Contribution to the Marine Science 27. Washington. pp. 179. 
Silva, P.C., P. W. Basson and R.L. Moe. 1996. Catalog of the benthic marine algae of the Indian Ocean. University of California Publications in Botany 79:1-1259.

Trowbridge, C.D. 1998. Ecology of the green macroalga Codium fragile (Suringar) Hariot 1889: invasive and non invasive subspecies. Ann. Rev. Oceanogr. Mar. Biol. 36: $1-64$.

Van den Hoek, C., D.G. Mann and H.M. Jahns. 1995. Algae, an Introduction to Phycology. Cambridge University Press, Cambridge. pp. 623.
Went, F.A.F.C.1889. Les modes de reproduction du Codium tomentosum. Nederl. Kruidk. Arch. Ser. 2, 5:440-444.

Yang, M.H., G. Blunden, F.L. Huang and R.L. Fletcher. 1997. Growth of a dissociated, filamentous stage of Codium species in laboratory culture. J. Appl. Phycol. 9: $1-3$.

Yotsui, T. and S. Migita. 1989. Cultivation of a green alga Codium fragile regeneration medullary threads. Nippon Suisan Gakkaishi 55: 41-44. 